\title{
Influenza: marketing vaccine by marketing disease
}

In table 1 of this Feature (BMJ 2013;346:f3037, doi:10.1136/ bmj.f3037), we would like to add a note that the surgeon general recommended, in 1960, that all pregnant women be vaccinated. ${ }^{1}$ The Centers for Disease Control and Prevention first made a specific recommendation for pregnant women in their second and third trimesters in $1997^{2}$ (not 2000, as stated in the table), and expanded this to all pregnant women in $2004^{3}$ (as stated in the table).
1 Burney LE Influenza immunization. Public Health Rep 1960:75:944.

2 Centers for Disease Control and Prevention. Prevention and control of influenza: recommendations of the Advisory Committee on Immunization Practices (ACIP). MMWR Recomm Rep 1997;46(RR-9):1-25.

3 Harper SA, Fukuda K, Uyeki TM, Cox NJ, Bridges CB. Prevention and control of influenza: recommendations of the Advisory Committee on Immunization Practices (ACIP). MMWR Recomm Rep 2004;53(RR-6):1-40.

Cite this as: BMJ 2013;347:f6770

๑ BMJ Publishing Group Ltd 2013 